\title{
Prevalence of asymptomatic bacteriuria in type 2 diabetic subjects with and without microalbuminuria
}

\author{
Athanasia Papazafiropoulou*1, loannis Daniil2, Alexios Sotiropoulos' ${ }^{1}$ Eleni Balampani², Anthi Kokolaki1, \\ Stavros Bousboulas', Stavroula Konstantopoulou², Eystathios Skliros'1, Dimitra Petropoulou² and Stavros Pappas
}

\begin{abstract}
Background: Diabetic subjects, especially women, show high prevalence of asymptomatic bacteriuria (ASB). The aim of the present study was to evaluate the prevalence of ASB in subjects with type 2 diabetes mellitus (T2D) with and without microalbuminuria (MA).

Findings: A hundred diabetic subjects with MA (53 males/47 females, mean age \pm standard deviation: $65.5 \pm 11.1$ years) and 100 diabetic subjects without MA (52 males/48 females, mean age \pm standard deviation: $65.4 \pm 11.3$ years), consecutively attending the outpatient diabetes clinic of our hospital were recruited in the study. Subjects with overt diabetic nephropathy or nephropathy from other causes were excluded. In addition, subjects with symptoms of urinary track infection or use of antimicrobial drugs in the last 14 days were excluded by the study.

Diabetic subjects with MA showed increased prevalence of ASB compared to diabetic subjects without MA (21\% versus $8 \%, \mathrm{P}<0.001$, respectively). Escherichia coli was the most prevalent pathogen isolated in diabetic subjects with and without MA ( $12 \%$ versus $3.0 \%, P=0.01$, respectively) followed by Proteus mirabilis ( $6 \%$ versus $5 \%, P=0.75$, respectively) and Klebsiella spp ( $5 \%$ versus $1 \%, P=0.09$, respectively). Univariate logistic analysis showed that ASB was associated with the presence of coronary artery disease [odds ratio (OR): $0.29,95 \%$ Confidence Intervals $(95 \% \mathrm{Cl})$ : $0.09-0.95, \mathrm{P}=0.04$ ] and gender (OR: $0.09,95 \% \mathrm{Cl}: 0.02-0.35, \mathrm{P}<0.001$ ) in the diabetic study group with $\mathrm{MA}$.

Conclusions: ASB is more prevalent among T2D subjects with MA. Screening for ASB is warranted in diabetic patients especially if pyuria is detected in urine analysis since ASB has been found to be a risk factor for developing symptomatic urinary tract infection.
\end{abstract}

\section{Background}

Urinary tract infections (UTIs) as well as their complications, such as emphysematous cystitis, pyelonephritis and renal papillary necrosis occur more commonly in subjects with type 2 diabetes mellitus (T2D) [1-3]. In addition, many studies have showed that diabetic subjects, especially women, show high prevalence of asymptomatic bacteriuria (ASB) [4-7]. In diabetic women, various risk factors for ASB have been suggested including age, presence of macroalbuminuria, low body mass index (BMI) and UTIs during the previous year [7]. In a prior study,

* Correspondence: pathan@ath.forthnet.gr

1 3rd Department of Internal Medicine and Center of Diabetes, General Hospital of Nikaia "Ag. Panteleimon" - Piraeus, Greece

Full list of author information is available at the end of the article
ASB was a risk factor for subsequent decline in renal function among women with type 1 diabetes mellitus [8].

Microalbuminuria (MA) is a common complication of T2D affecting almost $30-50 \%$ of the patients with T2D $[9,10]$. Presence of MA has been related with high blood pressure, dyslipidemia, inflammation, endothelial dysfunction, left ventricular hypertrophy and hypercoagulation [11]. However, little evidence exists regarding the relationship between ASB and MA in T2D subjects. Therefore, the aim of the present study was to evaluate the prevalence of ASB in T2D subjects with and without $\mathrm{MA}$ and to determine possible risk factors affecting the presence of ASB in diabetic subjects. 


\section{Methods}

A hundred diabetic subjects with MA (53 males/47 females, mean age \pm standard deviation: $65.5 \pm 11.1$ years) and 100 diabetic subjects without MA (52 males/ 48 females, mean age \pm standard deviation: $65.4 \pm 11.3$ years), consecutively attending the outpatient diabetes clinic of our hospital were recruited in the study. The physical examination and the interview of the subjects were carried based on a study protocol by the investigators. Subjects with overt diabetic nephropathy (proteinuria) or nephropathy from other causes were excluded. In addition, subjects with symptoms of UTI (including dysuria, frequency, fever, urgency and abdominal discomfort) or use of antimicrobial drugs in the last 14 days were excluded by the study.

All participants underwent complete physical examination in the morning of the study. They were questioned about previous and current diseases, use of medications and their smoking habits; ex-smokers who had given up smoking for a period of at least three years were considered as non-smokers. Retinopathy was reported from the medical records. Body weight with subjects in light clothing without shoes and height was measured and body mass index (BMI) was calculated. Waist circumference was measured with a soft tape on standing, midway between the lowest rib and the iliac crest.

Blood pressure was measured in the right arm three consecutive times, one minute apart, in the sitting position after 10 min resting period, using an appropriate cuff size. The mean value of the last two measurements was used in the statistical analysis. Arterial hypertension was defined according to the current guidelines if systolic blood pressure was $\geq 140 \mathrm{mmHg}$ and/or diastolic blood pressure $\geq 90 \mathrm{mmHg}$ or if patients were on antihypertensive treatment [12].

Blood was collected after an overnight fast of at least 12 hours. Serum glucose, lipids [total cholesterol, high density lipoprotein (HDL) cholesterol, triglycerides] and creatinine were measured enzymatically on a Technicon RAXT analyzer (Technicon Ltd, Dublin, Ireland). Low density lipoprotein (LDL) cholesterol was calculated using the formula of Friedwald et al [13]. Glomerular filtration rate was calculated according to the equation of Cockcroft and Gault [14]. $\mathrm{HbA}_{1 \mathrm{c}}$ was measured by HPLC (Roche diagnostics, Mannheim, Germany) with a nondiabetic reference range of 4.1-6.0\%. Microalbuminuria was diagnosed when albumin excretion rate (AER), measured by radioimmunoassay (RIA) (Pharmacia, Pharmacia and Upjon Diagnostics AB, Upsala, Sweden), was 30$300 \mathrm{mg} / 24$-hours in at least two out of three 24-hours urine collections over a three month period.

Midstream clean voiding urinary specimens were collected for urinalysis, microscopy, culture and sensitivity. The specimens were refrigerated immediately and cul- tured within 2 hours. All urine samples were cultured on Blood and MacConkey agar plates. The plates were incubated at $37^{\circ} \mathrm{C}$ aerobically for 48 hours. Bacteriuria was defined as the presence of at least $10^{5}$ colony forming units $/ \mathrm{ml}$ of 1 or 2 bacterial species in a culture of cleanvoided midstream urine confirmed by a second culture. Presence of at least three different microorganisms in a urine specimen was considered as contamination [15].

The study protocol was approved by the Scientific and Ethical Committee of the General Hospital of Nikaia. Full informed written consent was obtained from all patients.

\section{Statistical analysis}

Analyses were performed using the SPSS 15.0 (SPSS, IL, USA) statistical package. All variables were tested for normal distribution of the data. Data are presented as means \pm standard deviation or percentages. Differences between the studied groups examined using the student's unpaired $t$-test or the Mann-Whitney $U$-test for parametric and non-parametric data, respectively, while a chisquare test was used for categorical data. Bivariate correlations were performed using the Pearson or the Spearman correlation coefficient, as appropriate. Univariate binary logistic analysis was performed to look for the relationship between ASB and the variables of interest in the sample population. $P$ values $<0.05$ were considered statistically significant.

\section{Results}

\section{Subjects characteristics}

More diabetic subjects with MA had coronary artery disease (CAD) (39\% versus $23 \%, \mathrm{P}<0.01$, respectively) and hypertension ( $87 \%$ versus $72 \%, \mathrm{P}<0.001$, respectively) compared to diabetic subjects without MA. In addition, diabetic subjects with MA had higher levels of plasma urea $(P<0.001)$ and creatinine $(P=0.03)$ than diabetic subjects without MA. Patients with and without MA did not differ significantly in terms of age, BMI, duration of diabetes, glycemic control, systolic and diastolic arterial pressure, lipid profile, diabetic complications and treatment for diabetes (Table 1).

\section{Prevalence of ASB and isolated pathogens}

Diabetic subjects with MA showed increased prevalence of ASB compared to diabetic subjects without MA (21\% versus $8 \%, \mathrm{P}<0.001$, respectively). Escherichia coli was the most prevalent pathogen isolated in diabetic subjects with and without MA (12\% versus $3.0 \%, \mathrm{P}=0.01$, respectively) followed by Proteus mirabilis (6\% versus $5 \%, \mathrm{P}=$ 0.75 , respectively) and Klebsiella spp (5\% versus $1 \%, \mathrm{P}=$ 0.09 , respectively).

Univariate logistic analysis showed that ASB was associated with the presence of CAD [odds ratio (OR): 0.29, $95 \%$ Confidence Intervals (95\% CI): 0.09-0.95, P = 0.04] 
Table 1: Demographic and clinical characteristics of diabetic subjects with and without microalbuminuria (MA)

\begin{tabular}{lccc}
\hline & MA (+) & MA (-) & \multicolumn{1}{l}{} \\
& & & \\
\hline Males/females & $53 / 47$ & $52 / 48$ & 0.88 \\
& & & \\
Age (years) & $65.5 \pm 11.1$ & $65.4 \pm 11.3$ & 0.94 \\
Waist (cm) & $105.5 \pm 11.4$ & $104.1 \pm 12.5$ & 0.82 \\
Current smokers & 45 & 44 & 0.88 \\
Duration of diabetes (years) & $14.7 \pm 7.8$ & $13.6 \pm 8.2$ & 0.39 \\
HbA1c (\%) & $7.6 \pm 1.4$ & $8.1 \pm 1.4$ & 0.46 \\
Body mass index (Kg/m $\left.{ }^{2}\right)$ & $32.7 \pm 8.3$ & $31.4 \pm 6.2$ & 0.18 \\
Systolic blood pressure (mm & $140.9 \pm 18.1$ & $141.2 \pm 18.2$ & 0.92 \\
Hg) & & &
\end{tabular}

$\begin{array}{lccc}\begin{array}{l}\text { Diastolic blood pressure } \\ \text { (mm Hg) }\end{array} & 75.7 \pm 10.2 & 76.9 \pm 12.8 & 0.47 \\ & & & \\ \text { Glucose (mg/dl) } & 156.8 \pm 44.6 & 155.9 \pm 53.8 & 0.89 \\ \text { Total cholesterol (mg/dl) } & 178.3 \pm 54.9 & 176.6 \pm 38.4 & 0.81 \\ & & & \\ \text { HDL cholesterol (mg/dl) } & 48.6 \pm 14.7 & 49.9 \pm 15.2 & 0.54 \\ & & & \\ \text { LDL cholesterol (mg/dl) } & 98.8 \pm 35.5 & 101.3 \pm 32.7 & 0.54 \\ & & & \\ \text { Triglycerides (mg/dl) } & 145.4 \pm 38.0 & 133.9 \pm 32.9 & 0.34 \\ & & & \\ \text { Urea (mg/dl) } & 47.2 \pm 14.1 & 37.0 \pm 12.7 & <\mathbf{0 . 0 0 1} \\ & & & \\ \text { Creatinine (mg/dl) } & 1.1 \pm 0.6 & 0.9 \pm 0.3 & \mathbf{0 . 0 3} \\ \text { CAD (yes) } & 39 & 23 & \mathbf{0 . 0 1} \\ \text { Retinopathy (yes) } & 44 & 39 & 0.47 \\ \text { Hypertension (yes) } & 87 & 72 & <\mathbf{0 . 0 0 1} \\ \text { Hyperlipidemia (yes) } & 74 & 81 & 0.24 \\ \text { Treatment for diabetes } & - & - & - \\ \quad \text { Antidiabetic tablets } & 71 & 73 & 0.75 \\ \quad \text { Insulin } & 63 & 54 & 0.75\end{array}$

P values for the comparison between subjects with and without MA by independent samples t-test for continuous variables or by Pearson $\mathrm{X}^{2}$ for nominal variables.

HDL: high density lipoprotein; LDL: low density lipoprotein; CAD: coronary artery disease; PAD: peripheral artery disease.

and gender (OR: 0.09, 95\% CI: 0.02-0.35, P $<0.001)$ in the diabetic study group with MA. No any significant relationships were found between ASB and the rest of the variables. The same pattern was observed in diabetic study group without MA (Table 2).

\section{Discussion}

It is well documented that T2D patients showed increased prevalence of ASB [4-7]. The novel finding of the present study was that diabetic subjects with MA showed high prevalence of ASB compared to diabetics without MA. This result is in accordance with findings of two recent studies $[16,17]$. The first study showed that macroalbuminuria and serum creatinine were independent and significant risk factors for ASB in T2D women [16]. The second study, similarly, showed that the main risk factors for ASB in diabetic patients were female gender and urinary albumin excretion [17]. The same observation was made in type 1 diabetic (T1D) subjects. A study in children and adolescents with T1D showed that microalbuminuria and microvascular complications were significant risk factors for ASB [18]. In T1D women ASB was related with the presence of macroalbuminuria [7]. Therefore, a simply explanation might be that albuminuria, as an expression of structural damage in the kidney, might increase the vulnerability to bacterial attacks, thus resulting in an increased risk of developing ASB [7].

In the present study the most common isolated pathogen was Escherichia coli in diabetic subjects with and without MA. Previous studies have showed that Escherichia coli is the most common pathogen in diabetic subjects either with ASB or with clinical manifestations of UTIs $[19,20]$. However, one study had different results showing that Klebsiella spp was the most common pathogen in T2D subjects with ASB [21]. In the present study Klebsiella spp was the third in row isolated pathogen in both groups.

Confirming previous results [5-7] we showed that in the diabetic group with MA presence of ASB was related with female gender. Further analysis of our data showed a relationship between ASB and CAD in the diabetic study group with MA. A simply explanation is that the group with MA had more CAD subjects than the group without MA and this might in part explain the above finding. However, a study in outpatient women showed higher prevalence of CAD among women with ASB in comparison with women without ASB [22].

Despite evidence from previous studies $[7,23]$ we failed to show any relationship between ASB and age as well as BMI. However, other studies were in accordance with our results showing no significant association between ASB and age as well as BMI $[16,20,24]$. Also, no significant relationships were found between ASB and duration of diabetes, glycemic control and microvascular complications. However, the evidences by the literature are conflicting [6,7,25-27]. A study in T1D women showed that risk factors for ASB were a longer duration of diabetes and the presence of peripheral neuropathy [7]. In addition, presence of longstanding complications, such as 


\begin{tabular}{|c|c|c|c|c|c|c|}
\hline & \multicolumn{3}{|c|}{ MA (+) } & \multicolumn{3}{|c|}{ MA (-) } \\
\hline & Odds ratio & 95\% Confidence Intervals & P-value & Odds ratio & 95\% Confidence Intervals & P-value \\
\hline Gender (males vs. females) & 0.09 & $0.02-0.35$ & $<0.001$ & 0.98 & $0.88-1.17$ & 0.61 \\
\hline Age & 0.99 & $0.95-1.04$ & 0.98 & 1.01 & $0.94-1.08$ & 0.67 \\
\hline Waist & 0.97 & $0.85-1.02$ & 0.81 & 1.02 & $0.98-1.08$ & 0.81 \\
\hline Current smokers & 0.89 & $0.34-2.36$ & 0.82 & 1.30 & $0.31-5.51$ & 0.72 \\
\hline Duration of diabetes & 0.99 & $0.95-1.04$ & 0.91 & 1.05 & $0.97-1.14$ & 0.19 \\
\hline $\mathrm{HbA1c}$ & 0.78 & $0.52-1.16$ & 0.23 & 0.77 & $0.41-1.42$ & 0.41 \\
\hline Body mass index & 1.03 & $0.97-1.08$ & 0.30 & 1.05 & $0.96-1.16$ & 0.24 \\
\hline Systolic blood pressure & 0.99 & $0.96-1.02$ & 0.53 & 1.01 & $0.97-1.05$ & 0.41 \\
\hline Diastolic blood pressure & 0.99 & $0.94-1.04$ & 0.81 & 1.05 & $0.99-1.11$ & 0.09 \\
\hline Glucose & 0.99 & $0.98-1.00$ & 0.42 & 1.01 & $0.94-1.02$ & 0.21 \\
\hline Total cholesterol & 0.99 & $0.98-1.00$ & 0.29 & 1.01 & $0.99-1.02$ & 0.31 \\
\hline HDL cholesterol & 0.97 & $0.93-1.02$ & 0.30 & 1.05 & $0.97-1.09$ & 0.09 \\
\hline LDL cholesterol & 0.99 & $0.98-1.01$ & 0.49 & 1.02 & $0.97-1.04$ & 0.85 \\
\hline Triglycerides & 0.99 & 0.9901 .00 & 0.51 & 1.04 & $0.99-1.05$ & 0.25 \\
\hline Urea & 1.01 & $0.98-1.02$ & 0.58 & 1.02 & $0.97-1.07$ & 0.39 \\
\hline Creatinine & 0.79 & $0.30-2.11$ & 0.64 & 1.82 & $0.18-17.98$ & 0.61 \\
\hline$C A D$ & 0.29 & $0.09-0.95$ & 0.04 & 0.45 & $0.05-3.90$ & 0.47 \\
\hline Retinopathy & 0.94 & $0.35-2.49$ & 0.91 & 1.62 & $0.38-6.93$ & 0.51 \\
\hline Hypertension & 1.53 & $0.31-7.53$ & 0.59 & 0.62 & $0.14-2.71$ & 0.53 \\
\hline Hyperlipidemia & 1.64 & $0.49-5.42$ & 0.41 & 0.68 & $0.12-3.60$ & 0.65 \\
\hline
\end{tabular}

peripheral neuropathy and peripheral vascular disease has been showed to be associated with ASB [6,25]. However, these findings could not be confirmed by other studies $[26,27]$. Finally, in accordance with other studies, our data showed no significant associations between glycemic control, in terms of HbA1c, and ASB [7,8].

Our study has some limitations. First of all, as it is mentioned above, the two study groups were not comparable regarding the prevalence of CAD. In addition, the size of the study sample was rather small to conclude possible associations between ASB and the testing variables. Finally, as data were collected from a referral tertiary center, they cannot be extrapolated to the total diabetic population.
In conclusion, ASB is more prevalent among T2D subjects with MA. Screening for ASB is warranted in diabetic patients especially if pyuria is detected in urine analysis since ASB has been found to be a risk factor for developing symptomatic urinary tract infection [28].

Competing interests

The authors declare that they have no competing interests.

\section{Authors' contributions}

ID, EM and AK participated in the collection and analysis of urine samples and patient's medical history. AP, AS and ES participated in the design of the study and performed the statistical analysis and drafted the manuscript. SK, SB, DP and SP conceived of the study, and participated in its design and coordination. All authors read and approved the final manuscript.

Acknowledgements

No acknowledgments to made. 


\section{Author Details}

13rd Department of Internal Medicine and Center of Diabetes, General Hospital of Nikaia "Ag. Panteleimon" - Piraeus, Greece and 2Department of Microbiology, General Hospital of Nikaia "Ag. Panteleimon" - Piraeus, Greece

Received: 17 March 2010 Accepted: 17 June 2010

Published: 17 June 2010

\section{References}

1. Pozzilli P, Lesli RDG: Infections and diabetes: Mechanisms and prospects for prevention. Diabet Med 1994, 11:935-941.

2. Pappas S, Peppas ThA, Sotiropoulos A, Katsadoros D: Emphysematous pyelonephritis: a case report and review of the literature. Diabet Med 1993, 10:574-576.

3. Papazafiropoulou A, Daniil I, Sotiropoulos A, Petropoulou D, Konstantopoulou S, Peppas T, Pappas S: Urinary tract infection, uropathogens and antimicrobial resistance in diabetic and nondiabetic patients. Diabetes Res Clin Pract 2009, 85:e12-3.

4. Wheat LJ: Infection and diabetes mellitus. Diabetes care 1980, 3:187-197.

5. Nicolle LE: Asymptomatic bacteriuria in diabetic women. Diabetes care 2000, 23:722-723.

6. Zhanel GG, Nicolle LE, Harding GK: Prevalence of asymptomatic bacteriuria and associated host factors in women with diabetes mellitus. The Manitoba Diabetic Urinary Infection Study Group. Clin Infect Dis 1995, 21:316-322.

7. Geerlings SE, Stolk RP, Camps MJ, Netten PM, Hoekstra JB, Bouter PK, Braveboer B, Collet TJ, Jansz AR, Hoepelman AM: Asymptomatic bacteriuria may be considered a complication in women with diabetes. Diabetes Care 2000, 23:744-749.

8. Geerlings SE, Stolk RP, Camps MJ, Netten PM, Collet JT, Schneeberger PM, Hoepelman Al: Consequences of asymptomatic bacteriuria in women with diabetes mellitus. Arch Intern Med 2001, 161:1421-1427.

9. American Diabetes Association: Diabetic nephropathy. Diabetes Care 2003, 26(Suppl 1):S94-S98.

10. Ritz E, Orth SR: Nephropathy in patients with type 2 diabetes mellitus. NEngl J Med 1999, 341:1127-1133.

11. Maclsaac RJ, Cooper ME: Microalbuminuria and diabetic cardiovascular disease. Curr Atheroscler Rep 2003, 5:350-357.

12. Chobanian AV, Bakris GL, Black HR, Cushman WC, Green LA, Izzo JL Jr, Jones DW, Materson BJ, Oparil S, Wright JT Jr, Roccella EJ: Seventh report of the Joint National Committee on Prevention, Detection, Evaluation, and Treatment of High Blood Pressure. Hypertension 2003, 42:1206-1252. Joint National Committee on Prevention, Detection, Evaluation, and Treatment of High Blood Pressure. National Heart, Lung, and Blood Institute; National High Blood Pressure Education Program Coordinating Committee

13. Friedewald WT, Levy RI, Fredrickson DS: Estimation of the concentration of low-density lipoprotein cholesterol in plasma, without use of the preparative ultracentrifuge. Clin Chem 1972, 18:499-502.

14. Cockcroft D, Gault MH: Prediction of creatinine clearance from serum creatinine. Nephron 1976, 16:31-41.

15. Medical Research Council Bacteriuria Committee: Recommended terminology of urinary tract infection. BMJ 1979, 2:717-719.

16. Ishay A, Lavi I, Luboshitzky R: Prevalence and risk factors for asymptomatic bacteriuria in women with Type 2 diabetes mellitus. Diabet Med 2006, 23:185-188.

17. Matteucci E, Troilo A, Leonetti $\mathrm{P}$, Giampietro $\mathrm{O}$;: Significant bacteriuria in outpatient diabetic and non-diabetic persons. Diabet Med 2007 24:1455-1459

18. Salem MA, Matter RM, Abdelmaksoud AA, El Masry SA: Prevalence of asymptomatic bacteriuria in Egyptian children and adolescents with type 1 diabetes mellitus. J Egypt Soc Parasitol 2009, 39:951-962.

19. Bonadio M, Boldrini E, Forotti G, Matteucci E, Vigna A, Mori S, Giampietro $O$ : Asymptomatic bacteriuria in women with diabetes: influence of metabolic control. Clin Infect Dis 2004, 38:e41-45.

20. Boroumand MA, Sam L, Abbasi SH, Salarifar M, Kassaian E, Forghani S: Asymptomatic bacteriuria in type 2 Iranian diabetic women: a cross sectional study. BMC Women's Health 2006, 6:4.

21. Alebiosu CO, Osinupebi OA, Olajubu FA: Significant asymptomatic bacteriuria among Nigerian type 2 diabetics. J Natl Med Assoc 2003, 95:344-351.
22. Hermida JA Pérez, Loro JF Ferrer: Asymptomatic bacteriuria in women. Epidemiological, pathologic and therapeutic study. Arch Esp Urol 2004, 57:784-804

23. Odetoyin WB, Aboderin AO, Ikem RT, Kolawole BA, Oyelese AO: Asymptomatic bacteriuria in patients with diabetes mellitus in lle-lfe, South-West, Nigeria. East Afr Med J 2008, 85:18-23.

24. Turan H, Serefhanoglu K, Torun AN, Kulaksizoglu S, Kulaksizoglu M, Pamuk $B$, Arslan H: Frequency, risk factors, and responsible pathogenic microorganisms of asymptomatic bacteriuria in patients with type 2 diabetes mellitus. Jpn J Infect Dis 2008, 61:236-238

25. Schmitt JK, Fawcett CJ, Gullickson G: Asymptomatic bacteriuria and hemoglobin A1. Diabetes Care 1986, 9:518-520.

26. Brauner A, Flodin U, Hylander B, Ostenson CG: Bacteriuria, bacterial virulence and host factors in diabetic patients. Diabet Med 1993 10:550-554

27. Perez EL Luque, de la Luz M Villalpando, Malacara JM: Association of sexual activity and bacteriuria in women with noninsulin-dependent diabetes mellitus. J Diabetes Complications 1992, 6:254-257.

28. Ribera MC, Pascual R, Orozco D, Pérez C Barba, Pedrera V, Gil V: Incidence and risk factors associated with urinary tract infection in diabetic patients with and without asymptomatic bacteriuria. Eur J Clin Microbiol Infect Dis 2006, 25:389-393.

doi: $10.1186 / 1756-0500-3-169$

Cite this article as: Papazafiropoulou et al., Prevalence of asymptomatic bacteriuria in type 2 diabetic subjects with and without microalbuminuria $B M C$ Research Notes 2010, 3:169

\section{Submit your next manuscript to BioMed Centra and take full advantage of:}

- Convenient online submission

- Thorough peer review

- No space constraints or color figure charges

- Immediate publication on acceptance

- Inclusion in PubMed, CAS, Scopus and Google Scholar

- Research which is freely available for redistribution

Submit your manuscript at www.biomedcentral.com/submit
C) Biomed Central 